\title{
CO Hydrogenation over Alumina-Supported Sulfide Cluster Catalysts
}

Bimetallic Mo-Fe and Mo-Co sulfide clusters were anchored on $\mathrm{Al}_{2} \mathrm{O}_{3}$ and used for $\mathrm{CO}$ hydrogenation. In addition to methane, significant amounts of dimethyl ether were produced. The reaction orders obtained from power rate laws for methanation indicated that the surfaces of the catalytic ensembles were not completely saturated by $\mathrm{CO}$, in contrast to the observations for most conventional CO hydrogenation catalysts. A kinetic analysis and parameter estimation was performed to identify the rate-determining step for methanation. A catalytic cycle was postulated that could account not only for the formation of methane and higher hydrocarbons, but also for dimethyl ether as a primary product.

\author{
Levi T. Thompson, Jr. \\ Johannes Schwank \\ Department of Chemical Engineering \\ University of Michigan \\ Ann Arbor, Ml 48109
}

M. David Curtis

Department of Chemistry University of Michigan Ann Arbor, Ml 48109

\section{Introduction}

\section{Objectives and relevance}

One of the greatest challenges in heterogeneous catalysis is to elucidate how the nature of the active site influences catalytic behavior. The adsorption of reactant molecules, the formation of reaction intermediates, and ultimately the product distribution depend on the composition and structure of the catalytic surface sites. Catalysts derived from structurally well defined organometallic clusters are very attractive model systems insofar as they are amenable to detailed spectroscopic characterization and evaluation of the intrinsic kinetics that control their catalytic behavior. These types of catalysts may also provide a link between homogeneous catalysis, where the catalytic complexes are easily identified, and heterogeneous catalysis, where the surfaces tend to be quite irregular.

The objective of this study was to investigate the CO hydrogenation activities of catalysts prepared from organometallic sulfide clusters containing Mo and either $\mathrm{Fe}$ or $\mathrm{Co}$. Although the late transition metals are the most active catalysts for $\mathrm{CO}$ hydrogenation, they tend to be nonselective, with product distributions following the Anderson-Schulz-Flory relationship. The late transition metals are also extremely sensitive to poisoning by sulfur, which is a common impurity in synthesis gas. Molybdenum, on the other hand, in its oxide as well as its sulfide form exhibits remarkable tolerance to deactivation in $\mathrm{H}_{2} \mathrm{~S}$ and has proven activity for $\mathrm{CO}$ hydrogenation. Furthermore, the addition of $\mathrm{Fe}$ or $\mathrm{Co}$ to Mo appears to beneficially effect catalyst selectivity. Consequently, discrete organometallic clusters con-

Correspondence concerning this paper should be addressed to Johannes Schwank. taining $\mathrm{Mo}, \mathrm{S}$, and $\mathrm{Fe}$ (or $\mathrm{Co}$ ) represent attractive precursor compounds for the preparation of active, sulfur tolerant $\mathrm{CO}$ hydrogenation catalysts.

An attempt was made to identify the rate-determining step for methanation on these cluster-derived catalysts. To this end, the commonly accepted sequences of elementary reaction steps for the two most important methanation mechanisms, the $\mathrm{CO}$ insertion mechanism and the carbide mechanism, were evaluated. Finally, a catalytic cycle has been proposed to account for the total product distribution, including hydrocarbons and oxygenates.

\section{Significant prior work}

Typical commercial catalysts are prepared either by coprecipitation or by sequential adsorption of suitable precursor salt solutions onto a support, followed by treatment routines including drying, calcination, reduction, and/or sulfidation. For such conventional catalysts, it is very difficult to control the surface composition or define the nature of the active site. In addition, there is a tendency for significant portions of the metal to form inactive bulk particles or solid solutions with the support.

There is currently a great deal of interest in the use of organometallic clusters in the preparation of supported catalysts (Zwart and Snel, 1985; Gates et al., 1986). Because organometallic clusters can be synthesized easily and their structures are well defined, they offer an opportunity to examine the nature of the active site in catalytic reactions and rationally design catalysts. This becomes especially interesting for the preparation of bi- or multimetallic catalysts. Starting from heterobimetallic clusters, it is possible to synthesize bimetallic catalytic ensembles from metals that do not form bulk alloys. As a result, one 
can generate catalytic surfaces that would be unattainable by conventional catalyst preparation methods.

It is commonly accepted that coordinative unsaturation plays an important role in cluster catalysis. Therefore, particular attention has been focused on clusters that can undergo rapid and reversible ligand abstraction and addition. In most clusters, the energies required to activate metal-ligand bonds are also sufficient to break the metal-metal bonds, causing the undesirable disintegration of the cluster framework and aggregation of the metal (Psaro and Ugo, 1986; Yermakov, 1983; Phillips and Dumesic, 1984).

In attempts to overcome the instability of the cluster framework, researchers have investigated the use of clusters containing bridging or capping ligands. These bridging ligands appear to hold the cluster framework together even when the metalmetal bonds have been cleaved. An example of this approach is the bridged hydride in $\left\{\mathrm{HRhP}\left(\mathrm{OC}_{3} \mathrm{H}_{7}\right)_{3}\right\}_{2}$ (Muetterties, 1982), which was successfully used to catalyze the hydrogenation of alkenes and alkynes. In general, olefin hydrogenation can be accomplished under much milder reaction conditions than $\mathrm{CO}$ hydrogenation. Under typical $\mathrm{CO}$ hydrogenation conditions, most clusters disintegrate and aggregate into metallic or oxide particles (Choplin et al., 1983; Budge et al., 1985; Anderson et al., 1977). For $\mathrm{H}_{2} \mathrm{Os}(\mathrm{CO})_{4}$ supported on $\mathrm{MgO}$, the formation of two stable anions has been reported (Lamb and Gates, 1986). $\left[\mathrm{H}_{3} \mathrm{Os}_{4}(\mathrm{CO})_{12}\right]^{-}$has been identified as the active species for $\mathrm{CO}$ hydrogenation. Pierantozzi et al. (1983) isolated the carbido complex $\left[\mathrm{Ru}_{3} \mathrm{C}(\mathrm{CO})_{16}\right]^{2-}$ as a decomposition product of the reaction between $\mathrm{Ru}_{3}(\mathrm{CO})_{12}$ and $\mathrm{MgO}$ during $\mathrm{CO}$ hydrogenation. Carbides have also been reported to stabilize the dispersion of catalysts produced from $\mathrm{Fe}_{3}(\mathrm{CO})_{12}$ (Lazar et al., 1984).

In this work we report the use of heterobimetallic clusters containing bridging sulfide ligands as $\mathrm{CO}$ hydrogenation catalysts. In view of the demonstrated stability of metal-sulfur bonds, one would expect bridging sulfides to impart a high degree of structural integrity to the cluster. While the synthesis (Williams et al., 1983; Curtis and Williams, 1983; Curtis et al., 1986a) and characterization of these cluster-derived catalysts (Thompson et al., 1986; Curtis et al., 1986b) are discussed elsewhere, we focus here on their kinetic and mechanistic behavior in $\mathrm{CO}$ hydrogenation.

\section{Experimental Method Catalyst preparation}

Details concerning the synthesis of the bimetallic sulfide clusters containing Mo and either Fe or Co have been reported elsewhere (Williams, 1985; Curtis et al., 1986a). The MoFeS cluster $\left[(\mathrm{Cp})_{2} \mathrm{Mo}_{2} \mathrm{Fe}_{2} \mathrm{~S}_{2}(\mathrm{CO})_{8}\right]$ forms two isomers, with the metal atoms arranged either in a planar ( $\mathrm{pMoFeS}$ ) or in a butterfly (bMoFeS) configuration. Figure 1 shows the molecular structure of the bMoFeS cluster as determined by single crystal $\mathrm{X}$-ray diffraction. The metal atoms in the MoCoS cluster $\left[(\mathrm{Cp})_{2} \mathrm{Mo}_{2} \mathrm{Co}_{2} \mathrm{~S}_{3}(\mathrm{CO})_{4}\right]$ were also arranged in a butterfly configuration.

Strem $\gamma-\mathrm{Al}_{2} \mathrm{O}_{3}(92 \%$ purity, the balance water with only ppm levels of metal, BET surface area $225 \mathrm{~m}^{2} / \mathrm{g}$ ), calcined at $773 \mathrm{~K}$ in dry $\mathrm{O}_{2}$ for $12 \mathrm{~h}$, was used as the support. The pure clusters were dissolved in dried and distilled dichloromethane. The solution was contacted with the partially dehydroxylated $\gamma-\mathrm{Al}_{2} \mathrm{O}_{3}$, and the resulting slurry was stirred for approximately $30 \mathrm{~min}$.

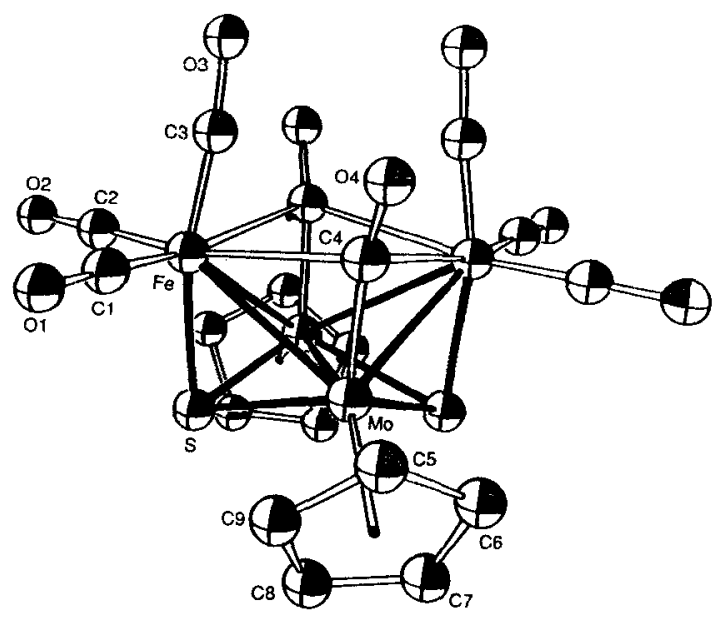

Figure 1. ORTEP plot of butterfly isomer of $(\mathrm{Cp})_{2} \mathrm{MO}_{2} \mathrm{Fe}_{2}\left(\mu_{\mathrm{e}} \mathrm{S}\right)_{2}(\mathrm{CO})_{8}$ cluster.

Based on structural characterization by single crystal $X$-ray diffraction

The supernatant solvent was removed under vacuum at ambient temperature, and the dried catalyst was stored under $\mathrm{N}_{2}$ atmosphere for subsequent use. The resulting catalysts had a total metal loading of about $1 \mathrm{wt} . \%$ and BET surface areas of $\approx 150$ $\mathrm{m}^{2} / \mathrm{g}$.

\section{Catalytic activity}

Kinetic experiments were carried out in a glass-lined, stainless steel U-tube reactor $(6.35 \mathrm{~mm}$ OD). A diagram of the automated flow reactor system is given in Figure 2. In a typical experiment, $300-500 \mathrm{mg}$ of catalyst was loaded into the reactor and secured between two quartz or Pyrex glass wool plugs. The reaction temperatures were measured using an Inconelsheathed iron-constantan thermocouple placed directly into the catalyst bed, and controlled to $\pm 1 \mathrm{~K}$ by an Omega $4002 \mathrm{KC}$ proportional controller. The reaction pressures were monitored by a pressure gauge mounted at the reactor inlet, and adjusted by a Nupro fine-metering valve at the reactor outlet. The effluent lines were heated to avoid condensation of product gases. All the tubing between the feed gas manifold and the gas chromato-

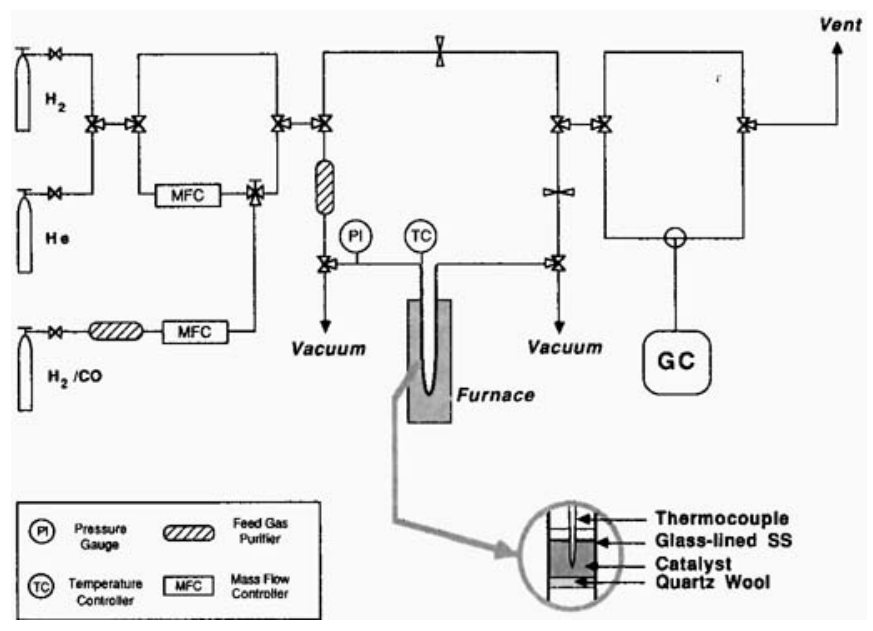

Figure 2. Flow reactor used for Co hydrogenation. 
graph used for product analysis was lined with Tefion to avoid the adverse effect of $\mathrm{H}_{2} \mathrm{~S}$ adsorption, and the possibility of metal carbonyl formation. Prepurified $\mathrm{He}, \mathrm{H}_{2}, \mathrm{H}_{2} / \mathrm{H}_{2} \mathrm{~S}$ (49 ppm), and $\mathrm{H}_{2} / \mathrm{CO}\left(24 \% \mathrm{CO}, 1 \% \mathrm{~N}_{2}\right.$, and $75 \% \mathrm{H}_{2}$ ) were metered using Tylan FC-260 mass flow controllers. The $\mathrm{H}_{2} / \mathrm{CO}$ stream was passed through an oxygen trap (Matheson Oxy-trap), and a column packed with a mixture of dry molecular sieves $(5 \AA)$, and activated carbon (Calgon). Hydrogen, $\mathrm{H}_{2} / \mathrm{H}_{2} \mathrm{~S}$, and $\mathrm{He}$ could be added to the $\mathrm{H}_{2} / \mathrm{CO}$ reactant stream through a cross-pattern valve. The final feed mixture was passed through a column of activated carbon to insure removal of trace metal carbonyls.

Freshly prepared catalyst samples were quickly loaded into the reactor to minimize air exposure, purged with $\mathrm{He}$, and slowly heated to $673 \mathrm{~K}$ at a rate of $1-2 \mathrm{~K} / \mathrm{min}$. Pyrolysis in $\mathrm{He}$ at $673 \mathrm{~K}$ for $4 \mathrm{~h}$ was followed by a similar pretreatment in $\mathrm{H}_{2}$ starting at room temperature. Typically, steady state activity was achieved after $\approx 10 \mathrm{~h}$ on stream, and reported activities were those after $20 \mathrm{~h}$ on stream unless otherwise noted. The following equation summarizes the determination of $\mathrm{CH}_{4}$ formal turnover frequencies, $N_{\mathrm{CH} 4}$ (Sivasanker et al., 1984):

$$
N_{\mathrm{CH} 4}=\frac{x_{\mathrm{CH} 4} \rho Q}{(W L / M)}
$$

Carbon monoxide conversion was limited to $5 \%$ to insure differential reaction conditions. After extended periods on stream (typically more than $25 \mathrm{~h}$ ), the reaction was stopped and the catalyst was treated in flowing $\mathrm{H}_{2}$ for $4 \mathrm{~h}$ at $673 \mathrm{~K}$ before starting the next $\mathrm{CO}$ hydrogenation run.

Effluent gases were analyzed using a Varian 3700 gas chromatograph (GC) with flame ionization and thermal conductivity detectors (FID, TCD) in series. The FID was specific to hydrocarbons and oxygenates. The TCD was unspecific, but provided excellent quantification of $\mathrm{O}_{2}, \mathrm{~N}_{2}$, and $\mathrm{CH}_{4}$ (tie component). A packed GC column system with a column switching routine allowed the separation of permanent gases from the other components. The gas samples first eluted through a $1.8 \mathrm{~m}$ Porapak QS column at $343 \mathrm{~K}$ with a $\mathrm{He}$ carrier gas flow rate of $0.5 \mathrm{~mL} / \mathrm{s}$. The permanent gases almost immediately eluted from the Porapak column and passed into a $0.9 \mathrm{~m}$ molecular sieve column, where they were trapped for subsequent analysis. The flow was redirected through a fine needle valve, adjusted to match the pressure drop across the molecular sieve column, into the TCD. Once $\mathrm{CO}_{2}$, ethane, and ethylene were quantified, the flow was reverted back through the molecular sieve, and $\mathrm{N}_{2}, \mathrm{O}_{2}, \mathrm{CH}_{4}$, and $\mathrm{CO}$ were quantified. Finally, the molecular sieve column was again bypassed, and the Porapak column was heated to 453 $\mathrm{K}$ at $30 \mathrm{~K} / \mathrm{min}$ for analysis of the remaining hydrocarbons and oxygenates. Sample injection, control of the column switching valves (Varian six-port valves with pneumatic actuators), and data acquisition were accomplished using a Varian 4270 programmable integrator. A Basic program was used to perform data reduction following each run. Additional details can be found elsewhere (Thompson, 1986).

\section{Results and Discussion}

\section{Activity and selectivity}

Following the standard pretreatment in $\mathrm{H}_{2}$ as outlined in the experimental section, the initial catalytic activity for $\mathrm{CO}$ hydrogenation was very low. During an induction period lasting 4 to

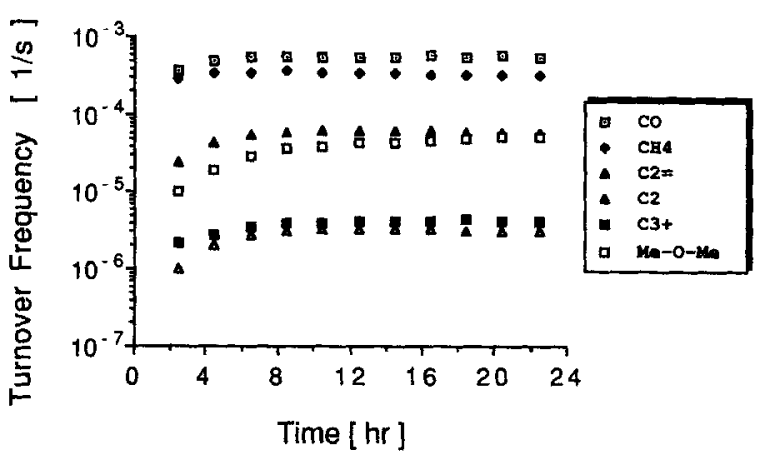

Figure 3. Activity of pMoFes $/ \mathrm{Al}_{2} \mathrm{O}_{3}$ catalysts as a function of time on stream.

$573 \mathrm{~K}$; total pressure, $859 \mathrm{kPa} ; \mathrm{H}_{2} / \mathrm{CO}$ feed ratio, $3: 1$

$10 \mathrm{~h}$, the activity increased to a steady state. Mössbauer spectroscopic results indicate that the oxidation state of the $\mathrm{Fe}$ is only slightly altered during this induction period (Thompson, 1986). For example, the $\mathrm{bMoFeS} / \mathrm{Al}_{2} \mathrm{O}_{3}$ catalyst contained a mixture of about $90 \% \mathrm{Fe}^{2+}$ with the balance $\mathrm{Fe}^{\partial+}(\partial<2)$ following $\mathrm{He}$ or $\mathrm{H}_{2}$ pretreatment at $673 \mathrm{~K}$, and following exposure to $\mathrm{H}_{2} / \mathrm{CO}$. Consequently, we believe that the induction periods were primarily the result of changes in the chemistry of the support or surface overlayer.

A typical time vs. activity plot is illustrated in Figure 3 for $\mathrm{pMoFeS} / \mathrm{Al}_{2} \mathrm{O}_{3}$. Similar plots were obtained for bMoFeS/ $\mathrm{Al}_{2} \mathrm{O}_{3}$ and $\mathrm{MoCoS} / \mathrm{Al}_{2} \mathrm{O}_{3}$, while the bare support was relatively inactive. When the used catalysts were treated for several hours in pure $\mathrm{H}_{2}$ at $673 \mathrm{~K}$, induction periods similar to those for the fresh catalyst were observed, followed by a steady state activity that matched the original level. These activity trends could be reproduced through several treatment and reaction cycles. Reproducible induction periods of this type are indicative of reversible surface redox reactions and/or changes in the chemistry of the surface overlayer. We do not believe the surface reconstructed. The steady state activities could be maintained for more than $300 \mathrm{~h}$ without noticeable signs of deactivation.

Exemplary Arrhenius plots of the steady-state methanation and hydrocarbon production activities at $859 \mathrm{kPa}$ are shown in Figures 4 and 5 , respectively. These activities were not altered

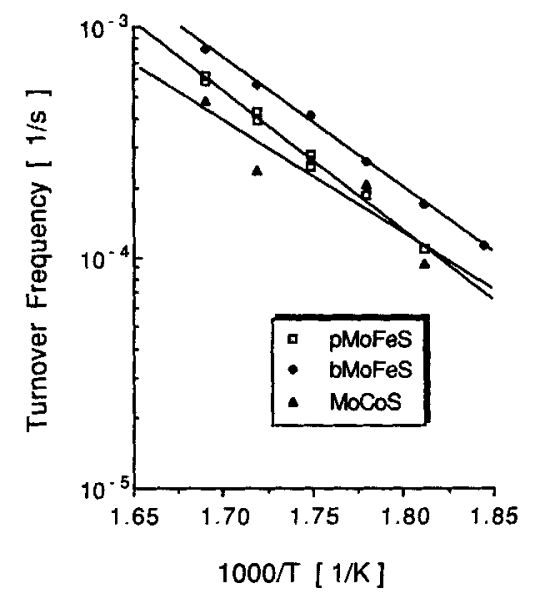

Figure 4. Arrhenius plot for methane formation over sulfide cluster derived catalysts. $859 \mathrm{kPa} ; \mathrm{H}_{2} / \mathrm{CO}$ feed ratio, $3: 1$ 


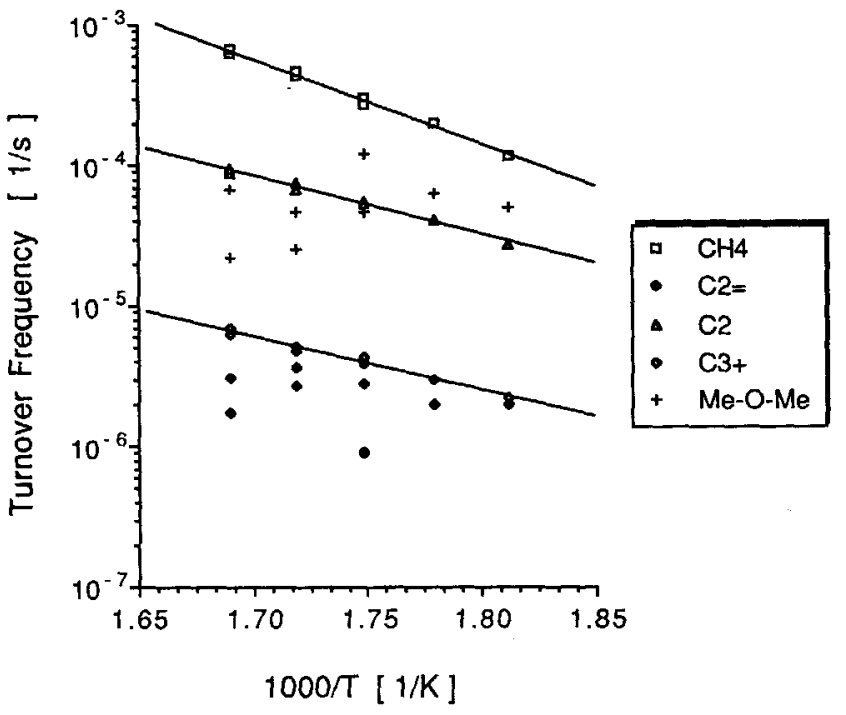

Figure 5. Arrhenius plot for hydrocarbon and oxygenate products over pMoFeS $/ \mathrm{Al}_{2} \mathrm{O}_{3}$. $859 \mathrm{kPa} ; \mathrm{H}_{2} / \mathrm{CO}$ feed ratio, 3:1

by the presence of $\mathrm{H}_{2} \mathrm{~S}$ in the reactant stream, Table 1 . This is consistent with behavior observed for cobalt molybdenum sulfide CO hydrogenation catalysts (Dianis, 1987). There were fundamental differences between the behavior of catalysts derived from the bimetallic sulfide clusters and those derived from the metal carbonyl clusters, Table 2 . The methanation activities were lower than those of the reduced monometallic catalysts (Brenner, 1986), but comparable to those reported for sulfided group VIII (Agrawal, 1979; Agrawal et al., 1981, 1982; Fitzharris et al., 1982) and sulfided Mo catalysts (Concha and Bartholomew, 1983). The activities were also similar in magnitude to those of well-dispersed Fe catalysts (Jung et al., 1982).

Significant amounts of dimethyl ether were produced over the iron-containing cluster catalysts. On MoCoS $/ \mathrm{Al}_{2} \mathrm{O}_{3}$, however, the production of dimethyl ether was not observed under similar reaction conditions. Figure 6 shows a comparison of the product distributions obtained on the three different catalysts. Ironbased (Storch et al., 1951) and potassium-promoted $\mathrm{MoS}_{2}$ and $\mathrm{MoS}_{2} / \mathrm{CoS}_{2}$ catalysts (Dianis, 1987) have been reported to produce oxygenates including dimethyl ether at high pressures. However, the production of large amounts of dimethyl ether at low pressures is unprecedented.

The selectivity to methane and dimethyl ether was not only dependent on the precursor cluster composition, but was also

Table 1. Effect of $\mathrm{H}_{2} \mathrm{~S}$ on Methanation Activity of $\mathrm{MoCaS} / \mathrm{Al}_{2} \mathrm{O}_{3}$

\begin{tabular}{lccccc}
\hline & & \multicolumn{3}{c}{$\begin{array}{c}\text { In situ } \\
\text { Sulfided }\end{array}$} \\
\hline Methanation activity, $1 / \mathrm{s} \times 10^{4}$ & 2.64 & 2.47 & 1.63 & 1.55 \\
$\mathrm{C}_{2} \mathrm{H}_{4} / \mathrm{C}_{2} \mathrm{H}_{6}$ & 0.15 & 0.15 & 0.09 & 0.10 \\
$\mathrm{CH}_{4}$ selectivity & 55.6 & 53.8 & 70.6 & 69.5 \\
Excess $\mathrm{CO}_{2} \%$ & 20 & 13 & -2 & 1 \\
$\mathrm{H}_{2} \mathrm{~S}$ in pretreatment stream, ppm & 50 & 0 & 0 & 0 \\
$\mathrm{H}_{2} \mathrm{~S}$ in feed stream, ppm & 0 & 0 & 0 & 27 \\
\hline
\end{tabular}

*Measured at $573 \mathrm{~K}, 859 \mathrm{kPa}, \mathrm{H}_{2} / \mathrm{CO}-3$

${ }^{* *}$ Measured at $573 \mathrm{~K}, 581 \mathrm{kPa}, \mathrm{H}_{2} / \mathrm{CO}-8$
Table 2. Methanation Activities for Sulfide and Carbonyl Cluster-Derived Catalysts*

\begin{tabular}{lllllc}
\hline & & \multicolumn{4}{c}{ Product Distribution } \\
\cline { 4 - 6 } \multicolumn{1}{c}{ Cluster } & Freq. 1/s & $\mathrm{CH}_{4}$ & $\mathrm{C}_{2}$ & $\mathrm{C}_{3}$ & Oxygenates \\
\hline pMoFeS & $7 \times 10^{-6}$ & 74 & 14 & 1 & 11 \\
bMoFeS & $6 \times 10^{-6}$ & 81 & 14 & 1 & 4 \\
$\mathrm{MoCoS}$ & $3 \times 10^{-6}$ & 72 & 25 & 3 & - \\
$\mathrm{Fe}_{3}(\mathrm{CO})_{12}$ & $2 \times 10^{-5 * *}$ & $19 \dagger$ & 73 & 8 & - \\
$\mathrm{Mo}_{2}(\mathrm{CO})_{6}$ & $2 \times 10^{-3 * *}$ & $86 \neq$ & 10 & 3 & - \\
$\mathrm{Co}_{2}(\mathrm{CO})_{8}$ & $3 \times 10^{-3 * *}$ & 53 & 15 & 33 & - \\
\hline
\end{tabular}

*Measured at or extrapolated to $523 \mathrm{~K}$, atmospheric pressure, $\mathrm{H}_{2} / \mathrm{CO}=3$

**Brenner, 1986

+Commereuc et al., 1980

$\ddagger$ Bowman and Burwell, 1980

very dependent on the catalyst pretreatment. Dimethyl ether formation was significantly greater over the catalyst pretreated in $\mathrm{He}$ at $673 \mathrm{~K}$ than over the catalyst pretreated in $\mathrm{H}_{2}$ at $673 \mathrm{~K}$, Figure 7. Nevertheless, the combined activities for methane and dimethyl ether formation were similar, $7.9 \times 10^{-5}$ molecules/ cluster/s for the He pretreated catalyst compared to $5.9 \times 10^{-5}$ molecules/cluster/s for the $\mathrm{H}_{2}$ pretreated catalyst. Perhaps methane and dimethyl ether compete for a common reaction intermediate. The rate of reaction of this common intermediate, perhaps a surface formyl species, could govern the overall $\mathrm{CO}$ turnover frequency.

We believe that the production of dimethyl ether at low pressures is due to the presence of heterogenized clusters (Zwart and Snel, 1985). It is well known that homogeneous catalysts are very selective to oxygenate formation (Sheldon, 1983). We do not, however, believe that the original cluster remains intact. Instead the results indicate the presence of highly dispersed catalytic ensembles that are uniquely related to the precursor sulfide cluster.

The catalytic behavior was dependent not so much on the treatment history of the catalysts as on the nature of treatment immediately preceding a given $\mathrm{CO}$ hydrogenation run. This clearly rules out irreversible changes by pretreatment-induced reconstruction. Perhaps reversible changes in the alumina surface chemistry caused the induction period. Due to the high dispersion (Thompson, 1986) of the catalytic ensembles, we expect changes in the alumina chemistry such as variations in the hydroxyl group configuration (Knözinger and Ratnasamy, 1978) to influence the catalytic behavior. It is well documented

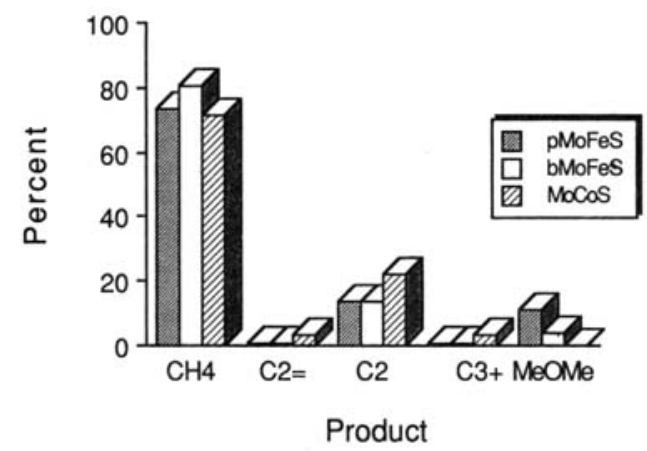

Figure 6. Product distributions obtained on sulfide cluster derived catalysts.

$573 \mathrm{~K}$; total pressure, $859 \mathrm{kPa} ; \mathrm{H}_{2} / \mathrm{CO}$ feed ratio, $3: 1$ 


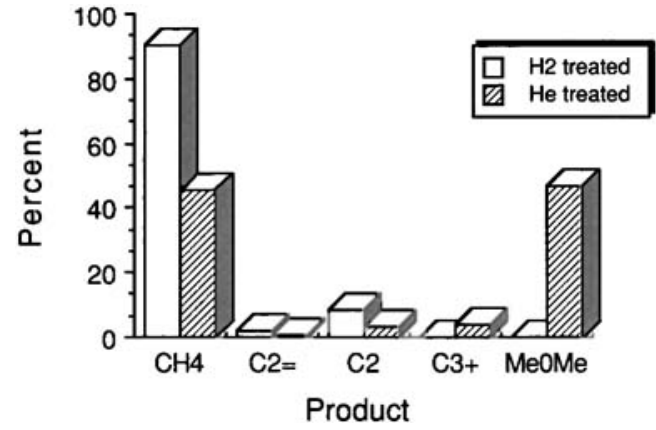

Figure 7. Effect of pretreatment on product distribution over bMoFeS $/ \mathrm{Al}_{2} \mathrm{O}_{3}$.

$573 \mathrm{~K}$; total pressure, $261 \mathrm{kPa}$

that the acid/base character of the support influences the catalytic behavior of anchored metal clusters. Over more basic supports such as $\mathrm{MgO}, \mathrm{ZnO}$, and $\mathrm{CaO}$, Rh carbonyl clusters exhibited a higher selectivity for methanol than on more acidic supports such as $\mathrm{SiO}_{2}$ or $\mathrm{Al}_{2} \mathrm{O}_{3}$ (Ichikawa, 1978). Furthermore, clusters on silica supports that were pretreated to decrease the acidity produced methanol, while the untreated silica catalyst produced mostly methane (Dirkse et al., 1982).

Dimethyl ether formation has been reported by Odebunmi et al. (1985) for $\mathrm{Al}_{2} \mathrm{O}_{3}$ supported catalysts prepared from Os clusters and by Pierantozzi (1987) for $\mathrm{ZrO}_{2} / \mathrm{Al}_{2} \mathrm{O}_{3}$ supported $\mathrm{K}\left[\mathrm{Fe}_{2} \mathrm{Mn}(\mathrm{CO})_{12}\right]$. They suggested that dimethyl ether was a secondary product stemming from the dehydration of methanol over acidic $\mathrm{Al}_{2} \mathrm{O}_{3}$ sites. It is well known that $\mathrm{Al}_{2} \mathrm{O}_{3}$ is active for methanol dehydration (Siddhan and Narayanan, 1981). Licht et al. (1980) also observed the dehydration of alcohols to ethers over acidic sites in $\mathrm{SiO}_{2}$ supported $\mathrm{Pt}$, $\mathrm{Ir}$, and $\mathrm{Rh}$ catalysts.

Several observations suggest that dimethyl ether is a primary product during $\mathrm{CO}$ hydrogenation over $\mathrm{Al}_{2} \mathrm{O}_{3}$ supported $\mathrm{MoFeS}$. Even at low conversions methanol was not detected in the product stream. If dimethyl ether were a secondary product we would expect to observe significant amounts of methanol. Pierantozzi (1987) observed that methanol selectivity increased with decreasing conversion. This is the expected behavior for species involved in secondary reactions; however, this was not observed in our work. It is unlikely that $100 \%$ of such large amounts of methanol could be converted to dimethyl ether via a secondary reaction given the high space velocities and low conversions used in our experiments. Furthermore, the acid sites required for methanol dehydration would be detrimental for methanol formation, according to Ichikawa (1978) and Dirkse et al. (1982), who suggest that basic supports favor methanol formation.

The activity of most methanation catalysts can be adequately described by an equation of the following form:

$$
N_{\mathrm{CH} 4}=A \exp \left(-\Delta E_{a} / R T\right)\left(p_{\mathrm{H} 2}\right)^{n}\left(p_{\mathrm{Co}}\right)^{m}
$$

Table 3 compares the kinetic parameters for the sulfide cluster derived catalysts with literature values for supported $\mathrm{Fe}$ and Co catalysts (Jung et al., 1982; Vannice, 1975) and Mo single crystals (Logan et al., 1985).

The preexponential factors were normalized to $101.3 \mathrm{kPa}$ total pressure for convenience. The apparent activation energies for methanation obtained for the sulfide cluster derived catalysts are in good agreement with values reported for conventionally prepared $\mathrm{CO}$ hydrogenation catalysts. Conversely, the apparent activation energies for $\mathrm{CO}$ consumption seemed low. According to Jung et al. (1982), low CO consumption activation energies may indicate high dispersion. We conclude that the sulfide cluster derived catalysts are highly dispersed. This conclusion is supported by high-resolution electron microscopic, $\mathrm{X}$-ray diffraction, and Mössbauer spectroscopic results (Thompson, 1986). In particular, electron microscopy did not detect particles under conditions that imaged 10-20 $\AA$ ensembles (Odebunmi et al., 1985).

The partial pressure dependences were positive for both $\mathrm{H}_{2}$ and $\mathrm{CO}$ and similar to dependences for Mo single crystals (Logan et al., 1985). Over $\mathrm{CO}$ hydrogenation catalysts such as $\mathrm{Fe}$, $\mathrm{Co}$, and $\mathrm{Ni}$, the reaction rate is near first order in $\mathrm{H}_{2}$ and zero order in $\mathrm{CO}$. Evidently, $\mathrm{CO}$ does not inhibit methanation over the sulfide cluster derived catalysts as it does over late transition metals. Although the apparent Arrhenius parameters given in Table 3 are useful for catalytic reactor design, they give little information concerning the reaction mechanism.

\section{Mechanistic aspects}

Background. From a fundamental standpoint, catalysts prepared from clusters that do not disintegrate and/or aggregate under reaction conditions or those that form stable, highly dispersed catalytic ensembles have an advantage over conventionally prepared catalysts (Ugo and Psaro, 1983; Muetterties and Stein, 1979). The well-defined nature of clusters allows a very confident investigation of their catalytic behavior at a molecular level. Using the appropriate kinetic models we can postulate the importance of elementary reactions and test various reaction mechanisms.

Table 3. Kinetic Parameters for Methanation According to Power Rate Law Expression*

\begin{tabular}{|c|c|c|c|c|c|}
\hline Catalyst & $\begin{array}{c}A \\
1 / \mathrm{s}\end{array}$ & $\begin{array}{c}\Delta E_{a} \\
\mathrm{~kJ} / \mathrm{mol}\end{array}$ & $n$ & $m$ & $\begin{array}{r}\Delta E_{a}(\mathrm{CO}) \\
\mathrm{kJ} / \mathrm{mol}\end{array}$ \\
\hline $\mathrm{pMoFeS} / \mathrm{Al}_{2} \mathrm{O}_{3}$ & $* * 2.1 \times 10^{3}$ & $85.2 \pm 5$ & $0.70 \pm 0.02$ & $0.37 \pm 0.09$ & 77 \\
\hline $\mathrm{bMoFeS} / \mathrm{Al}_{2} \mathrm{O}_{3}$ & $* * 3.8 \times 10^{4}$ & $97.9 \pm 16$ & $0.70 \pm 0.02$ & $0.34 \pm 0.02$ & 89 \\
\hline $\mathrm{M} C \mathrm{CoS} / \mathrm{Al}_{2} \mathrm{O}_{3}$ & $* * 2.7 \times 10^{2}$ & $79.7 \pm 12$ & $1.21 \pm 0.06$ & $0.14 \pm 0.01$ & 74 \\
\hline $15 \% \mathrm{Fe} / \mathrm{Al}_{2} \mathrm{O}_{3}($ Vannice, 1975$)$ & $2.2 \times 10^{7}$ & $89.2 \pm 4$ & $1.1 \pm 0.1$ & $-0.05 \pm 0.07$ & 108 \\
\hline $5.9 \% \mathrm{Fe} /$ Saran (Jung et al., 1982) & $2.1 \times 10^{6}$ & 90 & 1.1 & -0.07 & 75 \\
\hline $2 \% \mathrm{Co} / \mathrm{Al}_{2} \mathrm{O}_{3}$ (Vannice, 1975$)$ & $9.0 \times 10^{8}$ & $113.0 \pm 17$ & $1.2 \pm 0.2$ & $-0.5 \pm 0.3$ & 112 \\
\hline Mo(100) single crystal (Logan et al., 1985) & - & $100.5 \pm 4$ & 1.0 & 0.32 & - \\
\hline
\end{tabular}

$* N_{\mathrm{CH} 4}=A \exp \left(-\Delta E_{\mathrm{a}} / R T\right)\left(p \mathrm{H}_{2}\right)^{n}\left(p_{\mathrm{CO}}\right)^{m}$

**Assuming that each cluster represents a catalytic site 
To gain mechanistic information for methane formation over sulfide cluster derived catalysts, we evaluated the role of various elementary reaction steps for the two important $\mathrm{CO}$ hydrogenation reaction mechanisms (Bell, 1981), namely the CO insertion mechanism and the carbide mechanism.

The CO insertion mechanism assumes the associative adsorption of $\mathrm{CO}$. This mechanism allows for oxygenate formation, but does not directly account for the production of $\mathrm{CO}_{2}$. The production of $\mathrm{CO}_{2}$ has often been attributed to the water gas shift reaction. The following equations summarize the most important elementary reaction steps for a variation of the $\mathrm{CO}$ insertion mechanism:

$$
\begin{aligned}
& \mathrm{CO}+* \stackrel{k_{\mathrm{CO}}}{=} \mathrm{CO} \\
& \mathrm{H}_{2}+2 * \stackrel{k_{\mathrm{H} 2}}{=} 2 \mathrm{H} \\
& \mathrm{CO}+\underset{*}{\mathrm{H}} \stackrel{k_{1}}{\rightleftharpoons} \mathrm{HCO}+* \\
& \mathrm{HCO}+\underset{*}{\mathrm{H} \stackrel{k_{2}}{=}} \mathrm{HC} \mathrm{HO}+* \\
& \mathrm{HC} \underset{*}{\mathrm{CO}}+\underset{*}{\mathrm{H}} \stackrel{k_{3}}{\Longrightarrow} \underset{*}{\longrightarrow} \mathrm{H}+\mathrm{H}_{2} \mathrm{O} \\
& \underset{*}{\mathrm{C}} \mathrm{H}+\underset{*}{\mathrm{H}} \stackrel{k_{4}}{=} \underset{*}{\mathrm{C}} \mathrm{H}_{2}+* \\
& \mathrm{CH}_{2}+\underset{*}{\mathrm{H}} \stackrel{k_{5}}{\rightleftharpoons} \mathrm{CH}_{3}+* \\
& \mathrm{CH}_{3}+\underset{*}{\stackrel{k_{6}}{\rightleftharpoons}} \mathrm{CH}_{4}+* \\
& \mathrm{CH}_{4} \stackrel{k_{-\mathrm{CH} 4}}{\rightleftharpoons} \mathrm{CH}_{4}+* \\
& \mathrm{H}_{2} \mathrm{O} \stackrel{k_{-\mathrm{H} 2 \mathrm{O}}}{\rightleftharpoons} \mathrm{H}_{2} \mathrm{O}+*
\end{aligned}
$$

The carbide mechanism is based on the assumption that active atomic carbon initiates the $\mathrm{CO}$ hydrogenation reaction. Both $\mathrm{CO}$ and $\mathrm{H}_{2}$ are assumed to adsorb dissociatively. The most important elementary reaction steps are summarized below.

$$
\begin{gathered}
\mathrm{CO}+* \stackrel{k_{\mathrm{CO}}}{\rightleftharpoons} \mathrm{CO} \\
\mathrm{CO}+* \stackrel{k_{2}}{\rightleftharpoons} \underset{*}{\rightleftharpoons}+\underset{*}{\rightleftharpoons} \\
\mathrm{H}_{2}+2 * \stackrel{k_{\mathrm{H} 2}}{=} 2 \mathrm{H}
\end{gathered}
$$

$$
\begin{aligned}
& \underset{*}{\mathrm{C}}+\underset{*}{\mathrm{H}} \stackrel{k_{2}}{\rightleftharpoons} \underset{*}{\mathrm{C}} \mathrm{H}+* \\
& \underset{*}{\mathrm{C}} \mathrm{H}+\underset{*}{\mathrm{H}} \stackrel{k_{3}}{=} \underset{*}{\mathrm{C}} \mathrm{H}_{2}+* \\
& \underset{*}{\mathrm{C}} \mathrm{H}_{2}+\underset{*}{\mathrm{H}} \stackrel{k_{4}}{=} \underset{*}{\rightleftharpoons} \mathrm{H}_{3}+*
\end{aligned}
$$

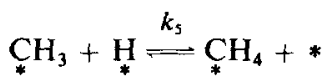

$$
\begin{aligned}
& \mathrm{O}+\underset{*}{\mathrm{CO}} \stackrel{k_{6}}{=} \mathrm{CO}_{2}+* \\
& \underset{*}{\mathrm{CH}_{4} \stackrel{k_{-\mathrm{CH}}}{\rightleftharpoons}} \mathrm{CH}_{4}+* \\
& \mathrm{CO}_{2} \stackrel{k_{-\mathrm{CO} 2}}{\rightleftharpoons} \mathrm{CO}_{2}+*
\end{aligned}
$$

The carbide mechanism readily accounts for the formation of methane, higher hydrocarbons, and $\mathrm{CO}_{2}$. It does not, however, explicitly address the production of oxygenates.

Kinetic Analysis and Parameter Estimation. Our analysis was based on a Langmuir-Hinshelwood or Hougen-Watson type kinetic model. Two of the key assumptions of this model are that the heats of adsorption are constant and the intrinsic reaction rates are proportional to the reactant surface coverages, $\theta_{i}$. To simplify the kinetic modeling, the existence of a single ratedetermining step and most abundant surface intermediate(s) was assumed. All the other reaction steps were assumed to be close to thermodynamic equilibrium. It was further assumed that over the temperature and pressure range investigated, the rate-determining step and the most abundant surface intermediates did not change. Each of the elementary reaction steps was considered as a candidate for the rate-determining step and provided the basis for the development of a mathematical formulation.

Using the $\mathrm{CO}$ insertion mechanism, we could, for example, consider the hydrogenation of the surface formyl group, Eq. 6, as the rate-determining step. The reaction rate would be described by the following expression:

$$
N_{\mathrm{CH} 4}=k_{2} \theta_{\mathrm{HCO}} \theta_{\mathrm{H}}
$$

Based on the assumption of thermodynamic equilibrium, the fractional surface coverages would be

$$
\begin{gathered}
\theta_{\mathrm{HCO}}=K_{\mathrm{I}} \theta_{\mathrm{CO}} \theta_{\mathrm{H}} / \theta_{v} \\
\theta_{\mathrm{H}}^{2}=K_{\mathrm{H} 2} p_{\mathrm{H} 2} \theta_{v}^{2} \\
\theta_{\mathrm{CO}}=K_{\mathrm{Co}} p_{\mathrm{Co}} \theta_{v}
\end{gathered}
$$

where $\theta_{v}$ represents the fractional surface vacancy. The low activities indicate that the surface was covered predominantly by $\mathrm{CO}$ and $\mathrm{H}$, so the fractional surface vacancy would be 
described by

$$
\theta_{v}=1-\theta_{\mathrm{CO}}-\theta_{\mathrm{H}}=\frac{1}{\left(1+\sqrt{K_{\mathrm{H} 2} p_{\mathrm{H} 2}}+K_{\mathrm{CO}} p_{\mathrm{CO}}\right)}
$$

Substitution into Eq. 23 leads to an overall reaction rate in terms of the partial pressures of $\mathrm{H}_{2}$ and $\mathrm{CO}$.

$$
\begin{aligned}
N_{\mathrm{CH} 4}=k_{2} K_{1} K_{\mathrm{H} 2} p_{\mathrm{H} 2} K_{\mathrm{CO}} p_{\mathrm{CO}}\left(\theta_{v}\right)^{2} & \\
= & k_{2} K_{1} \frac{K_{\mathrm{H} 2} p_{\mathrm{H} 2} K_{\mathrm{CO}} p_{\mathrm{CO}}}{\left(1+\sqrt{K_{\mathrm{H} 2} p_{\mathrm{H} 2}}+K_{\mathrm{CO}} p_{\mathrm{CO}}\right)^{2}}
\end{aligned}
$$

Rearranging this equation into the form

$$
\begin{aligned}
\sqrt{\frac{p_{\mathrm{H} 2} p_{\mathrm{CO}}}{N_{\mathrm{CH} 4}}=\frac{1}{\sqrt{k_{2} K_{1} K_{\mathrm{H} 2} K_{\mathrm{CO}}}}+\sqrt{\frac{p_{\mathrm{H} 2}}{k_{2} K_{1} K_{\mathrm{CO}}}}} \\
+\frac{\sqrt{K_{\mathrm{CO}}}}{\sqrt{k_{2} K_{1} K_{\mathrm{H} 2}}} p_{\mathrm{CO}}
\end{aligned}
$$

and numerical analysis yields $k_{2} K_{1}, K_{\mathrm{CO}}$, and $K_{\mathrm{H} 2}$. A similar algorithm was used to determine the coefficients for the other equations shown in Tables 4 and 5 .

Numerical values of the coefficients were obtained from regression analysis. Only one equation had nonnegative coefficients. Negative coefficients are obviously physically impossible, so the corresponding equations had to be eliminated from further consideration. The only equation with all positive coefficients had the following form:

$$
N_{\mathrm{CH} 4}=k \frac{K_{\mathrm{H} 2} p_{\mathrm{H} 2} K_{\mathrm{CO}} p_{\mathrm{Co}}}{\left(1+\sqrt{K_{\mathrm{H} 2} p_{\mathrm{H} 2}}+K_{\mathrm{CO}} p_{\mathrm{CO}}\right)^{2}}
$$

\begin{tabular}{|c|c|}
\hline Rate-Determining Step & Formulation \\
\hline \multirow{2}{*}{$\mathrm{CO}+* \stackrel{k_{\mathrm{CO}}}{=} \mathrm{CO}$} & $k_{\mathrm{CO}}^{\prime} K_{\mathrm{CO}} P_{\mathrm{CO}}$ \\
\hline & $\overline{1+\sqrt{K_{\mathrm{H} 2} \bar{P}_{\mathrm{H} 2}}+K_{\mathrm{CO}} P_{\mathrm{CO}}}$ \\
\hline \multirow{2}{*}{$\mathrm{H}_{2}+2 * \stackrel{k_{\mathrm{H} 2}}{\rightleftharpoons} 2 \mathrm{H}$} & $k_{\mathrm{H} 2}^{\prime} K_{\mathrm{H} 2} P_{\mathrm{H} 2}$ \\
\hline & $\left(1+\sqrt{K_{\mathrm{H} 2} P_{\mathrm{H} 2}}+K_{\mathrm{CO}} P_{\mathrm{CO}}\right)^{2}$ \\
\hline \multirow{2}{*}{$\mathrm{CO}+\mathrm{H}_{*}^{\stackrel{k_{1}}{=}} \mathrm{HCO}$} & $k_{1} K_{\mathrm{Co}} P_{\mathrm{Co}} \sqrt{K_{\mathrm{H} 2} P_{\mathrm{H} 2}}$ \\
\hline & $\left(1+\sqrt{K_{\mathrm{H} 2} P_{\mathrm{H} 2}}+K_{\mathrm{CO}} P_{\mathrm{CO}}\right)^{2}$ \\
\hline \multirow{2}{*}{$\mathrm{HCO}+\underset{*}{\mathrm{H}} \stackrel{k_{2}}{\rightleftharpoons} \mathrm{HCHO}$} & $k_{2}^{\prime} K_{\mathrm{Co}} P_{\mathrm{CO}} K_{\mathrm{H} 2} P_{\mathrm{H} 2}$ \\
\hline & $\left(1+\sqrt{K_{\mathrm{H} 2} P_{\mathrm{H} 2}}+K_{\mathrm{Co}} P_{\mathrm{Co}}\right)^{2}$ \\
\hline \multirow{2}{*}{$\mathrm{HCHO}+\underset{*}{\mathrm{H}} \stackrel{k_{3}}{\rightleftarrows} \mathrm{CH}+\mathrm{H}_{2} \mathrm{O}$} & $k_{3}^{\prime} K_{\mathrm{Co}} P_{\mathrm{Co}}\left(K_{\mathrm{H} 2} P_{\mathrm{H} 2}\right)^{3 / 2}$ \\
\hline & 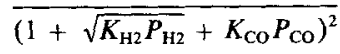 \\
\hline
\end{tabular}

This equation matches the formulation for the $\mathrm{CO}$ insertion mechanism with the hydrogenation of a surface formyl as the

Table 4. Model Equations for Various Rate-Determining Steps in CO Insertion Mechanism

\begin{tabular}{|c|c|}
\hline Rate-Determining Step & Formulation \\
\hline \multirow{2}{*}{$\mathrm{CO}+* \stackrel{k_{\mathrm{co}}}{\rightleftharpoons} \mathrm{CO}$} & $k_{\mathrm{co}}^{\prime} K_{\mathrm{CO}} P_{\mathrm{Co}}$ \\
\hline & $1+\sqrt{K_{\mathrm{H} 2} \bar{P}_{\mathrm{H} 2}}+K_{\mathrm{Co}} P_{\mathrm{Co}}$ \\
\hline \multirow{2}{*}{$\mathrm{H}_{2}+2 * \stackrel{k_{\mathrm{H} 2}}{\rightleftharpoons} 2 \mathrm{H}$} & $k_{\mathrm{H} 2}^{\prime} K_{\mathrm{H} 2} P_{\mathrm{H} 2}$ \\
\hline & 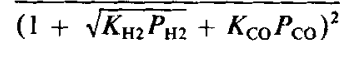 \\
\hline \multirow{2}{*}{$\mathrm{CO}+\stackrel{k_{1}}{=} \underset{*}{=}+\underset{*}{\mathrm{O}}$} & $k_{1} K_{\mathrm{Co}} P_{\mathrm{Co}}$ \\
\hline & $\left(1+\sqrt{K_{\mathrm{H} 2} P_{\mathrm{H} 2}}+K_{\mathrm{CO}} P_{\mathrm{CO}}\right)^{2}$ \\
\hline \multirow{2}{*}{$\underset{*}{\mathrm{C}}+\underset{*}{\mathrm{H}} \stackrel{k_{2}}{\rightleftharpoons} \underset{*}{\rightleftharpoons} \mathrm{H}+*$} & $k_{2}^{\prime} K_{\mathrm{Co}} P_{\mathrm{Co}} \sqrt{K_{\mathrm{H} 2} P_{\mathrm{H} 2}}$ \\
\hline & 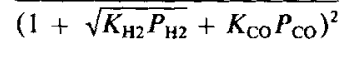 \\
\hline \multirow{2}{*}{$\underset{*}{\mathrm{H}}+\underset{*}{\mathrm{H}} \stackrel{k_{3}}{=} \mathrm{CH}_{2}+*$} & $k_{3}^{\prime} K_{\mathrm{CO}} P_{\mathrm{CO}} K_{\mathrm{H} 2} P_{\mathrm{H} 2}$ \\
\hline & $\left(1+\sqrt{K_{\mathrm{H} 2} P_{\mathrm{H} 2}}+K_{\mathrm{CO}} P_{\mathrm{CO}}\right)^{2}$ \\
\hline \multirow{2}{*}{$\mathrm{CH}_{2}+\mathrm{H} \stackrel{k_{3}}{=} \mathrm{CH}_{3}+*$} & $k_{4}^{\prime} K_{\mathrm{CO}} P_{\mathrm{CO}}\left(K_{\mathrm{H} 2} P_{\mathrm{H} 2}\right)^{3 / 2}$ \\
\hline & 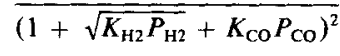 \\
\hline
\end{tabular}

$$
\begin{aligned}
k_{\mathrm{CO}}^{\prime} & =k_{\mathrm{CO}} / K_{\mathrm{CO}} \\
k_{\mathrm{H2}}^{\prime} & =k_{\mathrm{H} 2} / K_{\mathrm{H} 2} \\
k_{2}^{\prime} & =k_{2} K_{1}
\end{aligned}
$$$$
k_{3}^{\prime}=k_{3} K_{2} K_{1}
$$

Table 5. Model Equations for Various Rate-Determining Steps in Carbide Mechanism

rate-determining step, and the formulation for the carbide mechanism with the hydrogenation of a surface methylidyne as the rate-determining step. If the hydrogenation of a surface methylidyne were the rate-determining step, the reaction rate could be described by

$$
N_{\mathrm{CH} 4}=k_{3} \theta_{\mathrm{CH}} \theta_{\mathrm{H}}
$$

where the surface coverages at thermodynamic equilibrium are

$$
\begin{gathered}
\theta_{\mathrm{CH}}=\frac{K_{2} \theta_{\mathrm{C}} \theta_{\mathrm{H}}}{\theta_{v}} \\
\theta_{\mathrm{C}}=\frac{K_{1} \theta_{\mathrm{CO}} \theta_{v}}{\theta_{\mathrm{O}}}
\end{gathered}
$$

The surface coverage by atomic oxygen, $\theta_{0}$, was estimated using the quasisteady-state approximation. With this assumption the atomic oxygen coverage would be

$$
\theta_{\mathrm{O}} \approx\left(\frac{k_{1} \theta_{\mathrm{CO}}+k_{-6} \theta_{\mathrm{CO} 2}}{k_{6} \theta_{\mathrm{CO}}+k_{-1} \theta_{\mathrm{C}}}\right) \theta_{v}
$$

Under differential conditions the forward reaction rates would be more significant than the reverse reaction rates, therefore

$$
\theta_{0} \approx \frac{k_{1} \theta_{v}}{k_{6}}
$$

Substitution of these expressions along with expressions for $\theta_{\mathrm{Co}}$ and $\theta_{\mathrm{H}}$ into Eq. 31 leads to the following rate equation:

$$
N_{\mathrm{CH} 4}=\frac{k_{3} K_{2}\left(k_{6} / k_{-1}\right) K_{\mathrm{H} 2} p_{\mathrm{H} 2} K_{\mathrm{CO}} p_{\mathrm{CO}}}{\left(1+\sqrt{K_{\mathrm{H} 2} p_{\mathrm{H} 2}}+K_{\mathrm{CO}} p_{\mathrm{CO}}\right)^{2}}
$$

Numerical analysis would yield $k_{3} K_{2}\left(k_{6} / k_{-1}\right), K_{\mathrm{H} 2}$, and $K_{\mathrm{CO}}$. 
Discrimination between the $\mathrm{CO}$ insertion and carbide mechanisms was left to a consideration of the product distributions. Figure 8 illustrates the fit of the above equation for pMoFeS/ $\mathrm{Al}_{2} \mathrm{O}_{3}$ to the experimental data for varying reactant partial pressures. Similar fits were obtained for the other catalysts.

We also investigated the temperature dependence of the coefficients in Eq. 30 for methanation over pMoFeS $/ \mathrm{Al}_{2} \mathrm{O}_{3}$. The coefficients were determined from experimental data obtained at 553, 573, and $593 \mathrm{~K}$. From Arrhenius plots, the apparent activation energies and heats of adsorption for $\mathrm{CO}$ and $\mathrm{H}_{2}$ were determined. The resulting relationships are listed below.

$$
\begin{aligned}
& k=3.22 \times 10^{9} \exp (-135,000 / R T) \quad(1 / \mathrm{s}) \\
& K_{\mathrm{H} 2}=2.39 \times 10^{-8} \exp (54,100 / R T) \quad(1 / \mathrm{kPa}) \\
& K_{\mathrm{CO}}=7.00 \times 10^{-6} \exp (38,200 / R T)
\end{aligned}
$$

Here the rate constant corresponds to $k_{2} K_{1}$ for the $\mathrm{CO}$ insertion mechanism or $k_{3} K_{2}\left(k_{6} / k_{-1}\right)$ for the carbide mechanism. The apparent activation energy of the rate constant for the methanation, $135 \mathrm{~kJ} / \mathrm{mol}$, is similar to typical literature values, which range from 80 to $130 \mathrm{~kJ} / \mathrm{mol}$. The experimentally determined heat of adsorption of $\mathrm{H}_{2}(-54.1 \mathrm{~kJ} / \mathrm{mol})$ is close to that reported for dissociative adsorption onto organometallic clusters such as planar Ir complexes $(-59.0 \mathrm{~kJ} / \mathrm{mol}$ ) (Henrici-Olivé and Olivé, 1984). The heat of associative $\mathrm{CO}$ adsorption of -38.2 $\mathrm{kJ} / \mathrm{mol}$ is somewhat lower than the values reported for $\mathrm{M}-\mathrm{CO}$ bond energies in typical carbonyl clusters, which are generally about $-100 \mathrm{~kJ} / \mathrm{mol}$. This suggests that $\mathrm{CO}$ adsorbed on pMoFeS $/ \mathrm{Al}_{2} \mathrm{O}_{3}$ is more labile than $\mathrm{CO}$ ligands in typical carbonyl clusters. This difference is also qualitatively supported by temperature-programmed desorption studies where the $\mathrm{CO}$ ligands of the supported MoFeS or MoCoS clusters desorb at about $373 \mathrm{~K}$, while the unsupported clusters are stable to their melting points of $461 \mathrm{~K}$ for pMoFeS, $495 \mathrm{~K}$ for bMoFeS, and $451 \mathrm{~K}$ for MoCoS (Williams, 1985).

To test the model, methane turnover frequencies were predicted for partial pressures and temperatures outside the range of experimental data used for the regression analysis. The predicted results compared quite favorably with the experimental ones.

Catalytic Routes to Methane and Dimethyl Ether: A Proposed Reaction Mechanism. The kinetic information assembled in this study provided a basis for formulating reaction mechanisms which could account for:

1. The formation of methane and higher hydrocarbons

2. The primary formation of dimethyl ether

While dimethyl ether formation has generally been assumed to be due to secondary reactions of methanol (Odebunmi et al., 1985), we attempted to develop an alternate mechanism that could provide a primary route to dimethyl ether formation. This attempt was motivated by the observation that methanol, a postulated intermediate for dimethyl ether formation, never appeared, not even as a trace, in the reactor effluent. Furthermore, the differential reaction conditions employed in our investigation would not favor secondary reactions of primary products.

Figure 9 shows a hypothetical catalytic cycle based in part on the $\mathrm{CO}$ insertion mechanism that could in principle account for both methane and dimethyl ether formation. The salient features of this cycle are as follows. Associatively adsorbed $\mathrm{CO}$ is

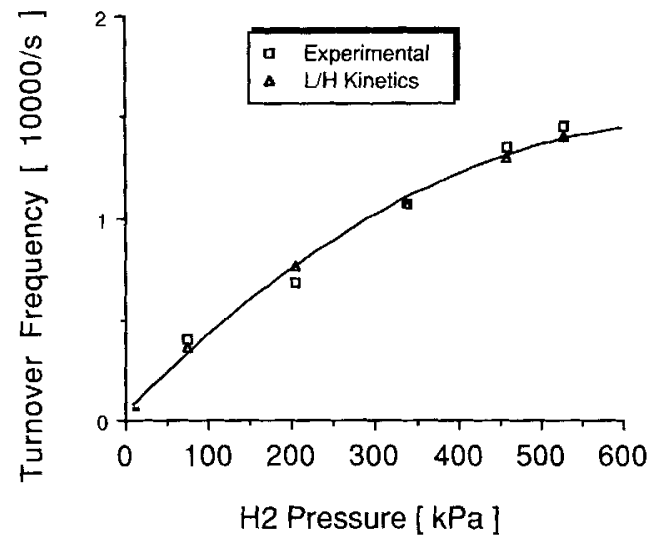

Figure 8. Comparison of experimental results at $573 \mathrm{~K}$ with kinetic model equation for bMoFeS $/ \mathrm{Al}_{2} \mathrm{O}_{3}$.

first inserted into a metal hydride bond to produce a surface formyl species. Stable transition metal formyl complexes have been identified (Wayland and Woods, 1981; Sweet and Graham, 1979; Gladysz, 1982; Cameron et al., 1983), supporting the feasibility of formyl reaction intermediates. Once such a formyl intermediate is formed, it could follow one of two possible routes. Routes I and II lead to the formation of methane and other hydrocarbons, and the formation of dimethyl ether,

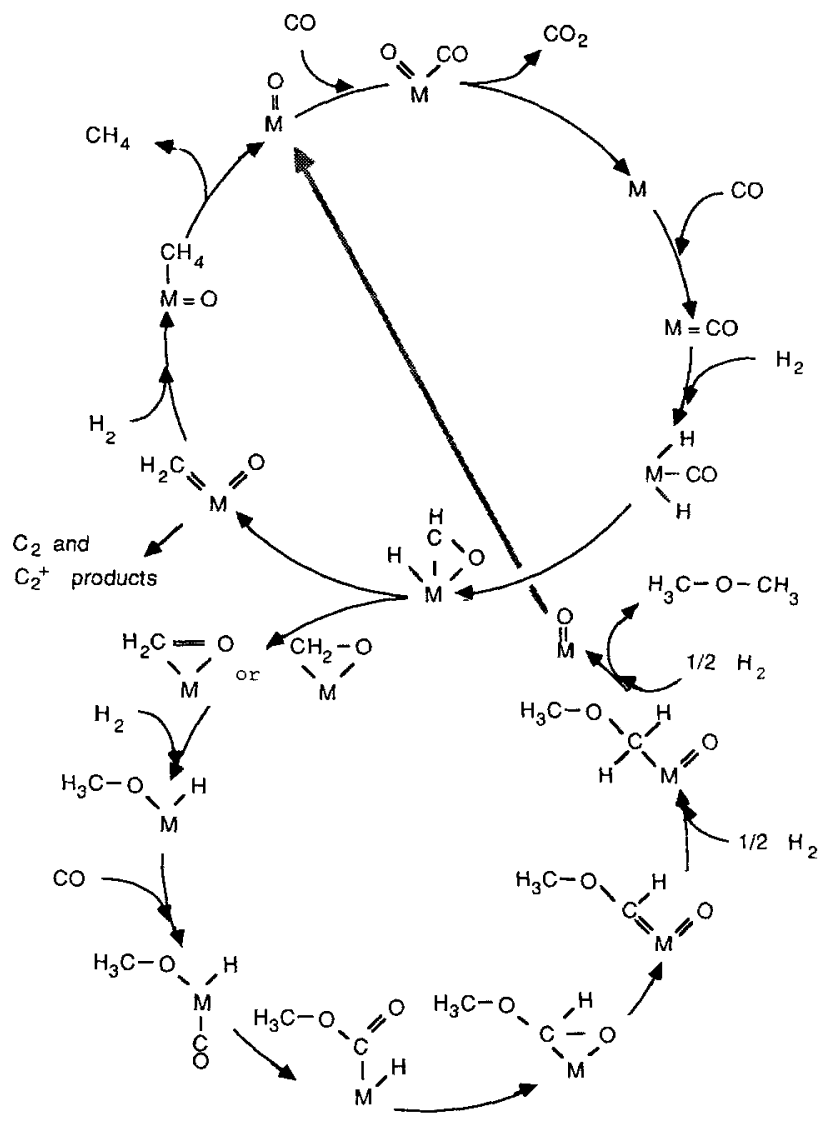

Figure 9. Proposed catalytic cycle accounting for dimethyl ether as primary reaction product. $M$ denotes a catalytic site, not a metal atom 
respectively. We do not want to imply that the dissociatively adsorbed $\mathrm{CO}$ is not contributing. The proposed catalytic cycle is simply our most reasonable attempt to rationalize the primary production of methane and dimethyl ether.

Route $I$ is initiated by the hydrogenation of the surface formyl to produce an oxo methylene species for which there are numerous organometallic analogs (Wengrovius and Schrock, 1982). Our kinetic modeling discussed in the previous section suggested that this type of step may be rate limiting in the production of methane. The resulting methylene species could be hydrogenated to methane or oligomerized to higher hydrocarbons. Oxygen could be removed from the catalytic site by reduction with $\mathrm{CO}$, resulting in the formation of $\mathrm{CO}_{2}$ as a primary product. This cycle accounts for the primary production of methane and $\mathrm{CO}_{2}$ without generating $\mathrm{H}_{2} \mathrm{O}$. This is important because our experimental results showed large quantities of $\mathrm{CO}_{2}$, but no measurable quantities of $\mathrm{H}_{2} \mathrm{O}$ in the product stream. The primary formation of $\mathrm{CO}_{2}$ is a novel feature, in that $\mathrm{H}_{2} \mathrm{O}$ is a primary product in the classic $\mathrm{CO}$ insertion mechanism. The production of $\mathrm{CO}_{2}$ is supposed to be the result of the water gas shift reaction.

Route II also is initiated by the hydrogenation of a surface formyl species at the carbon atom to produce an adsorbed formaldehyde species. Aldehyde-transition metal complexes have been prepared (Brown et al., 1979; Fahey, 1981; Gambarotta et al., 1982), and they appear to be important intermediates in CO hydrogenation by organometallic complexes (Muetterties and Stein, 1979) and olefin hydroformylation (Sheldon, 1983). Hydrogenation of the formaldehyde could result in the formation of a methoxide which also has organometallic analogs (Wolczanski and Bercaw, 1980) followed by the insertion of $\mathrm{CO}$ into the $\mathrm{M}-\mathrm{O}$ bond to produce a surface ester (Casey et al., 1979). Hydrogenation of the carbonyl oxygen and dehydration could yield an oxo methoxymethylene, another step modeled after a known organometallic reaction (Wong et al., 1979). Desorption of dimethyl ether and the oxidation of $\mathrm{CO}$ frees the active site for adsorption of another CO molecule. Many of the steps in this cycle have been proposed for the production of alcohols and other oxygenates such as aldehydes and esters (Bradley, 1979; Knifton, 1981; Rathke and Feder, 1978).

The key concept of this proposed catalytic cycle is the dual route for hydrogenation of the surface formyl group. Our mechanistic analysis suggested that the hydrogenation of a surface formyl species to an oxo methylene species may have been the rate-determining step for methane formation. Although our data do not provide sufficient proof, we can envision the hydrogenation of the formyl group to $\pi$-bonded formaldehyde as the corresponding rate-determining step for dimethyl ether formation.

We propose that Br $\phi$ nsted acidity favors the production of methane via route $I$, while Lewis acidity favors the production of dimethyl ether via route $1 \mathrm{I}$. It is well known that acidic solids such as $\mathrm{Al}_{2} \mathrm{O}_{3}$ contain both $\mathrm{Br} \phi$ nsted and Lewis acid sites with a broad distribution of acid strength and character. The surface acidity is dynamic in nature and is dependent on a number of factors, including pretreatment, reaction conditions, and amounts of adsorbed water. Helium pretreatment would be expected to remove water and favor the production of Lewis acid sites, while hydrogen pretreatment at elevated temperatures is likely to generate Br $\phi$ nsted acid sites (Tanabe, 1970). Furthermore, Lewis acid sites are known to stabilize $\pi$-bonded formal- dehyde (Fagan et al., 1981), the proposed intermediate to dimethyl ether via route II.

The chemistry of the cluster-derived catalytic ensembles does not appear to be substantially affected by treatment in $\mathrm{He}$ or $\mathrm{H}_{2}$, based on Mössbauer spectroscopic results (Thompson, 1986). Consequently, we propose that the acidic nature of the support in the immediate vicinity of the catalytic ensemble influences the product distribution (Vannice and Sudhakar, 1984).

The strength of the model is that it accounts for the primary production of both methane and dimethyl ether. There are, however, obvious weaknesses in the model. First and foremost, it relies heavily on the existence of surface intermediates that have not been experimentally identified. Instead, we inferred their existence based on documented analogs in organometallic cluster chemistry. Second, the kinetic analysis and parameter estimation did not allow us to unambiguously distinguish the $\mathrm{CO}$ insertion mechanism from the carbide mechanism. Finally, although we are quite confident that our reaction conditions preclude secondary reactions in the classic sense, we cannot completely rule out that two methanol intermediates are formed on the same primary catalytic site or on two adjacent sites followed by dehydration on nearby acidic sites of the $\mathrm{Al}_{2} \mathrm{O}_{3}$ support. This scenario is rather unlikely in view of the high dispersion and low loading of the catalytic ensembles. Furthermore, the complete absence of methanol in the products is a compelling sign that methanol is not the precursor to dimethyl ether or methane.

The dual scheme proposed here for methanation and simultaneous production of dimethyl ether is not only consistent with our own experimental observations but might be useful in rationalizing the formation of dimethyl ether over other cluster derived catalyst systems (Odebunmi et al., 1985; Pierantozzi, 1987). It represents an attractive mechanistic proposition deserving further theoretical and experimental scrutiny and discussion.

\section{Conclusions}

The cluster-derived bimetallic Mo-Fe and Mo-Co sulfide catalysts proved to be active for $\mathrm{CO}$ hydrogenation. After an induction period, the activity increased to a steady state that could be maintained for more than $300 \mathrm{~h}$ on stream without noticeable deactivation. The overall activity was similar to that of conventionally prepared, sulfided Mo or Fe catalysts.

In addition to methane and other typical Fischer-Tropsch reaction products, the Mo-Fe catalysts produced a significant amount of dimethyl ether under differential reaction conditions. In contrast the Mo-Co catalysts did not produce dimethyl ether. The dimethyl ether selectivity of the Mo-Fe catalysts appeared to be dependent on the pretreatment and reaction conditions. Treatment in $\mathrm{He}$ at $673 \mathrm{~K}$ resulted in much higher dimethyl ether selectivities than treatment in $\mathrm{H}_{2}$. Dimethyl ether is generally believed to be the product of a secondary reaction of methanol which is dehydrated over acidic sites found on supports such as $\mathrm{Al}_{2} \mathrm{O}_{3}$. In our case, the experimental conditions were not conducive for secondary reactions, suggesting that dimethyl ether might be a primary reaction product. This hypothesis is supported by the total absence of methanol from the product stream.

Reaction orders and apparent activation energies for methanation were in good agreement with those reported for molybdenum and molybdenum sulfides (Logan et al., 1985). A more 
extensive evaluation of the reaction kinetics enabled us to single out a rate-determining step from the commonly accepted sequence of elementary reaction steps for both the carbide and the $\mathrm{CO}$ insertion mechanisms. The results were consistent with the rate-determining step being either the hydrogenation of a surface methylidyne (for the carbide mechanism) or the hydrogenation of a surface formyl (for the $\mathrm{CO}$ insertion mechanism).

The kinetic analysis alone did not permit an unambiguous decision between these two possible mechanisms. However, discrimination between the two mechanisms could be accomplished by taking into account the product distribution. In view of the production of dimethyl ether, a strong case can be made for the contribution of the $\mathrm{CO}$ insertion mechanism, since the carbide mechanism in a classical sense does not readily account for oxygenates. Parallel pathways to methane and other hydrocarbons via the carbide mechanism, and to dimethyl ether via the $\mathrm{CO}$ insertion mechanism, cannot be ruled out.

A hypothetical model and catalytic cycle were developed to rationalize the primary formation of both methane and dimethyl ether. The key feature of this model is a formyl intermediate as the common point of departure into two different reaction routes. The first route of the cycle leads to methane formation, while the other leads to dimethyl ether formation without requiring methanol as an intermediate. The individual reaction steps in each route were modeled after demonstrated organometallic reaction analogs.

\section{Acknowledgment}

Partial support of this work by the Michigan Memorial-Phoenix Project is gratefully acknowledged. The authors would also like to express their appreciation to P.D. Williams for his contribution to the synthesis of the clusters. L.T. Thompson, Jr., would like to acknowledge support from the Graduate Professional Opportunity Program (GPOP) and the Rackham University Fellowship provided by the University of Michigan.

\section{Notation}

$A=$ preexponential factor in Arrhenius relationship

$\Delta E_{a}=$ apparent activation energy

$K=$ equilibrium constant

$k=$ rate constant

$L=$ fractional cluster loading

$M=$ metal weight per cluster

$m=$ reaction order with respect to $\mathrm{CO}$

$N=$ turnover frequency

$n=$ reaction order with respect to $\mathrm{H}_{2}$

$P=$ partial pressure

$Q=$ volumetric gas flow rate

$R=$ gas constant

$T=$ temperature

$W=$ weight of catalyst

$x=$ mole fraction

* = surface site

\section{Greek letters}

$\theta_{i}=$ fractional surface coverage of $i$ th component

$\theta_{v}=$ fractional surface vacancy

$\rho=$ molar density of gas

\section{Literature Cited}

Agrawal, P. K., "Surface and Reaction Studies of the Poisoning of Transition Metal Methanation Catalysts," Ph.D. Thesis, Univ. Delaware, Newark (1979).

Agrawal, P. K., J. R. Katzer, and W. H. Manogue, "Methanation over Transition Metal Catalysts. III: $\mathrm{Co} / \mathrm{Al}_{2} \mathrm{O}_{3}$ in Sulfur-Poisoning Studies," J. Catal., 69, 327 (1981).
Kinetic, "Methanation over Transition Metal Catalysts. V: $\mathbf{R u} / \mathrm{Al}_{2} \mathrm{O}$

Anderson, J. R., P. S. Elmes, R. F. Howe, and D. E. Mainwaring, "Preparation of Some Supported Metallic Cluster Catalysts," J. Catal., 50, 508 (1977).

Bell, A. T., "Catalytic Synthesis of Hydrocarbons over Group VIII Metals. A Discussion of the Reaction Mechanism," Catal. Rev. Sci. Eng., 23, 203 (1981).

Bowman, R. G., and R. L. Burwell, Jr., "The Reaction between Hydrogen and Carbon Monoxide on Catalysts Derived from $\mathrm{Mo}(\mathrm{CO})_{6}$ / $\mathrm{Al}_{2} \mathrm{O}_{3}, " J$. Catal., 63, 463 (1980).

Bradley, J. S., "Homogeneous Carbon Monoxide Hydrogenation to Methanol Catalyzed by Soluble Ruthenium Complexes," $J$. Am. Chem. Soc. 101, 7419 (1979).

Brenner, A., "Comparative Catalytic Activity of Supported Clusters," Metal Clusters, M. Moskovits, ed., John Wiley, New York, 249 (1986).

Brown, K. L., G. R. Clark, C. E. L. Headford, K. Marsden, and W. R. Roper, "Organometallic Models for Possible Fischer-Tropsch Intermediates. Synthesis, Structure, and Reactions of a Formaldehyde Complex of Osmium," J. Am. Chem. Soc., 101, 503 (1979).

Budge, J. R., B. F. Lücke, B. C. Gates, and J. Toran, "Metal Segregation in Supported Bimetallic Catalysts: $\gamma-\mathrm{Al}_{2} \mathrm{O}_{3}$-Supported $\mathrm{CO} \mathrm{Hy}$ drogenation Catalysts Prepared from $\mathrm{RhOs}_{3}, \mathrm{Rh}_{4}$, and $\mathrm{FeOs}_{3}$ Clusters," J. Catal., 91, 272 (1985).

Cameron, A., V. H. Smith, and M. C. Baird, "Oxidatively Induced Migration of Hydrogen from Metal to Carbon Monoxide," Organometallics, 2, 465 (1983).

Casey, C. P., M. A. Andrews, and J. E. Rinz, "Rhenium Formyl and Carbonyl Complexes Derived from the $\left(\mathrm{C}_{3} \mathrm{H}_{5}\right) \mathrm{Re}(\mathrm{CO})_{2}(\mathrm{NO})^{+}$ Cation: Models for the Fischer-Tropsch and Water Gas Shift Reactions," J. Am. Chem. Soc., 101, 741 (1979).

Choplin, A., M. LeConte, J. M. Basset, S. G. Shore, and W. L. Hsu, "Bimetallic Catalysts Starting from Heteropolymetallic Clusters: Surface Organometallic Chemistry and Fischer-Tropsch Activity of an Fe-Os System," J. Mol. Catal., 21, 389 (1983).

Commereuc, D., Y. Chauvin, F. Hugues, J. M. Basset, and D. Olivier, "Catalytic Synthesis of Low Molecular Weight Olefins from $\mathrm{CO}$ and $\mathrm{H}_{2}$ with $\mathrm{Fe}(\mathrm{CO})_{5}, \mathrm{Fe}_{3}(\mathrm{CO})_{12}$, and $\left[\mathrm{HFe}_{3}(\mathrm{CO})_{11}\right]-$ Supported on Inorganic Oxides," J. Chem. Soc.Chem. Commun, 154 (1980)

Concha, B. E., and C. H. Bartholomew, "Correlation of $\mathrm{O}_{2}$ Uptake with $\mathrm{CO}$ Hydrogenation Activity of Unsupported $\mathrm{MoS}_{2}$ Catalysts," J. Catal., 79, 327 (1983).

Curtis, M. D., and P. D. Williams, "Facile Synthesis of $\mathrm{Cp}_{2} \mathbf{M o}_{2}$ ( $\mu$ $\left.\mathrm{SH}_{2}\right)(\mu-\mathrm{S})_{2}$ and Its Use in Heterobimetallic Cluster Synthesis," Inorg. Chem., 19, 2661 (1983).

Curtis, M. D., J. Schwank, L. T. Thompson, and P. D. Williams, "Bimetallic Cluster Catalysts," U.S. Pat. 4,605,751 (Aug. 12, 1986a).

Curtis, M. D., J. Schwank, L. T. Thompson, P. D. Williams, and O. Baralt, "Methanation and HDS Catalysts Based on Sulfided, Bimetallic Clusters," Am. Chem. Soc., Div. Fuel Chem. Prepr., 31, 44 (1986b).

Dianis, W. P., "Characterization of Metal Sulfide Fischer-Tropsch Catalysts by Temperature-Programmed Desorption," Appl. Catal., 30, 99 (1987).

Dirkse, H. A., P. W. Lednor, and P. C. Versloot, “Alkali Metal-Naphthalene Adducts as Reagents for Neutralizing Oxide Surfaces and the Effect of Alkali Metal Treated Surfaces in Rh-Catalyzed Synthesis Gas $\left(\mathrm{CO}+\mathrm{H}_{2}\right)$ Conversion," J. Chem. Sac., Chem. Commun., 814 (1982).

Fagan, P. J., K. G. Moloy, and T. J. Marks, "Carbon Monoxide Activation by Organoactinides. Migratory $\mathrm{CO}$ Insertion into Metal-Hydrogen Bonds to Produce Mononuclear Formyls," J. Am. Chem. Soc., 103, 6959 (1981).

Fahey, D. R., "Rational Mechanism for Homogeneous Hydrogenation of Carbon Monoxide to Alcohols, Polyols, and Esters," J. Am. Chem. Soc., 103, 136 (1981).

Fitzharris, W. D., J. R. Katzer, and W. H. Manogue, "Sulfur Deactivation of Nickel Methanation Catalysts," J. Catal., 76, 369 (1982).

Gambarotta, S., C. Floriani, A. Chiesi-Villa, and C. Guastini, "MetalFormaldehyde Chemistry: Coordination, Disproportionation, and Lewis Acid Promoted Transformation to Oxomethylene Derivatives," J. Am. Chem. Soc., 104, 2020 (1982).

Gates, B. C., L. Guczi, and H. Knözinger, eds., Metal Clusters in Catalysis, Elsevier, New York (1986). 
Gladysz, J. A., "Transition Metal Formyl Complexes," Adv. Organometal. Chem., 20, 1 (1982).

Henrici-Olivé, $\mathrm{G}$,, and $\mathrm{S}$. Olivé, The Chemistry of the Catalyzed Hydrogenation of Carbon Monoxide, Springer, New York, 9 (1984).

Ichikawa, M., "Catalysis by Supported Metal Crystallites from Carbonyl Clusters. I: Catalytic Methanol Synthesis under Mild Conditions over Supported Rhodium, Platinum, and Iridium Crystallites Prepared from $\mathrm{Rh}, \mathrm{Pt}$, and Ir Carbonyl Cluster Compounds Deposited on $\mathrm{ZnO}$ and $\mathrm{MgO}, "$ Bull. Chem. Soc. Japan, 51, 2268 (1978)

Jung, H.-J., P. L. Walker, and M. A. Vannice, "CO Hydrogenation over Well-Dispersed Carbon-Supported Iron Catalysts," J. Catal., 75, 416 (1982).

Knifton, J. F., "Ethylene Glycol from Synthesis Gas via Ruthenium Melt Catalyst," J. Am. Chem. Soc., 103, 3959 (1981).

Knözinger, H., and P. Ratnasamy, "Catalytic Aluminas: Surface Models and Characterization of Surface Sites," Catal. Rev. Sci. Eng., 17, 31 (1978).

Lamb, H., and B. C. Gates, "Molecular Organo-osmium Chemistry and Catalysis on the Basic Magnesium Oxide Surface," J. Am. Chem. Soc., 108, 81 (1986).

Lázár, K., K. Matusek, J. Mink, S. Dobos, L. Guczi, A. Vizi-Orosz, L. Markó, and W. M. Reiff, "Spectroscopic and Catalytic Studies on Metal Carbonyl Clusters Supported on Cab-O-Sil. II: Impregnation and Decomposition of $\mathrm{Ru}_{3}(\mathrm{CO})_{12}$ and the Mixture of $\mathrm{Ru}_{3}(\mathrm{CO})_{12}$ and $\mathrm{Fe}_{3}(\mathrm{CO})_{12}$,"J. Catal., 87, 179 (1984).

Licht, E., Y. Schächter, and H. Pines, "Reactions of Primary and Secondary Alcohols over Platinum-, Iridium-, and Rhodium-Silica (CabO-Sil) Catalysts in the Presence of Hydrogen: Variables Affecting Ether Formation," J. Catal., 61, 109 (1980).

Logan, M., A. Gellman, and G. A. Somorjai, "Hydrogenation of Carbon Monoxide on Mo(100) Single Crystals and Polycrystalline Foils," J. Catal., 94, 60 (1985).

Muetterties, E. L., "Metal Cluster: Bridges between Molecular and Solid State Chemistry," Chem. Eng. News, 30 Aug., 28 (1982).

Muetterties, E. L., and J. Stein, "Mechanistic Features of Catalytic Carbon Monoxide Hydrogenation Reactions," Chem. Rev., 79(6), 479 (1979).

Odebunmi, E. O., B. A. Matrana, A. K. Datye, L. F. Allard, Jr., J. Schwank, W. H. Manogue, A. Hayman, J. H. Onuferko, H. Knözinger, and B. C. Gates, "CO Hydrogenation Catalyzed by AluminaSupported Osmium: Particle Size Effects," J. Catal., 95, 370 (1985)

Phillips, J., and J. A. Dumesic, "Production of Supported Metal Catalysts by the Decomposition of Metal Carbonyls," Appl. Catal., 9, 1 (1984).

Pierantozzi, R. "Synthesis of Oxygenates from $\mathrm{CO}$ and Hydrogen over Supported Metal Clusters," J. Catal., 106, 323 (1987)

Pierantozzi, R., E. G. Valagene, A. F. Nordquist, and P. N. Dyer, "Support and Cluster Effects on Synthesis Gas Conversion with Supported Ruthenium Clusters," J. Mol. Catal., 21, 189 (1983).

Psaro, R., and R. Ugo, "Metal Clusters on Unfunctionalized Inorganic Oxides," Metal Clusters in Catalysis, B. C. Gates, L. Guczi, H. Knözinger, eds., Elsevier, New York, 427 (1986).

Rathke, J. W., and H. M. Feder, "Catalysis of Carbon Monoxide Hydrogenation by Soluble Mononuclear Complexes," J. Am. Chem. Soc., 100, 3623 (1978).

Sheldon, R. A., Chemicals from Synthesis Gas, Reidel, Boston, 53 (1983).
Siddhan, S., and K. Narayanan, "Dehydration of Alcohols Over Alumina: Effect of Sodium Impregnation on the Mode of Elimination," $J$. Catal. 68, 383 (1981).

Sivasanker, S., E. P. Vesodharan, C. Sudhakar, A. Brenner, and C. B. Murchison, "Fischer-Tropsch Synthesis over Supported Molybdenum Hexacarbonyl," J. Catal., 87, 514 (1984).

Storch, H. H., N. Golumbic, and R. B. Anderson, The Fischer-Tropsch and Related Syntheses, Wiley, New York, 231 (1951).

Sweet, J. R., and W. A. Graham, "Reduction of Coordinated Carbon Monoxide, Formyl and Hydroxymethyl Ligands: Models for FischerTropsch and Related Reactions," J. Organometal. Chem., 173, C9 (1979).

Tanabe, K., Solid Acids and Bases, Their Catalytic Properties, Academic Press, New York, 45 (1970).

Thompson, L. T., Jr., "Bimetallic Sulfide Clusters for Fischer-Tropsch Synthesis and Hydrodesulfurization," Ph.D. Thesis, Univ. Michigan, Ann Arbor (1986).

Thompson, L.T., Jr., M. D. Curtis, and J. Schwank, "Bimetallic Sulfide Cluster Catalysts," Proc. World Cong. III Chem. Eng., Tokyo, IV, 426 (1986)

Ugo, R., and R. Psaro, "Transition Metal Carbonyl Cluster Chemistry: Some New Aspects of Carbon Monoxide Catalysis," J. Mol. Catal., 20, 53 (1983).

Vannice, M. A., "The Catalytic Synthesis of Hydrocarbons from $\mathrm{H}_{2}$ / CO Mixtures over the Group VIII Metals. I: The Specific Activities and Product Distributions of Supported Metals," J. Catal., 37, 449 (1975).

Vannice, M. A., and C. Sudhakar, "A Model for the Metal-Support Effect Enhancing CO Hydrogenation Rates over $\mathrm{Pt}^{-\mathrm{TiO}_{2}}$ Catalysts," J. Phys. Chem., 88, 2429 (1984)

Wayland, B. B., and B. A. Woods, "Observation of a Neutral Metalloformyl Complex Formed by the Reaction of Rhodium Octaethylporphyrin Hydride with Carbon Monoxide," J. Chem. Soc. Chem. Commun., 700 (1981).

Wengrovius, J. H., and R. R. Schrock, "Synthesis and Characterization of Tungsten Oxo Neopentylidene Complexes," Organometallics, 1, 148 (1982)

Williams, P. D., "Rational Syntheses of Tetranuclear Metal Sulfur Clusters and their Utility as Catalytic Precursors," Ph.D. Thesis, Univ. Michigan, Ann Arbor (1985).

Williams, P. D., M. D. Curtis, D. N. Duffy, and W. M. Butler, "MetalMetal Multiple Bonds in Rational Cluster Synthesis. Novel Isomerism in Iron-Molybdenum-Sulfur Clusters and a Molybdenum-Sulfur Cubane. Structure of $\left(\eta^{5}-\mathrm{CH}_{3} \mathrm{C}_{5} \mathrm{H}_{4}\right)_{2} \mathrm{Mo}_{2} \mathrm{Fe}_{2}\left(\mu_{3}-\mathrm{S}\right)_{2}(\mathrm{CO})_{6}(\mu-\mathrm{CO})_{2}$," Organometallics, 2, 165 (1983).

Wolczanski, P. J., and J. L. Bercaw, "On the Mechanisms of Carbon Monoxide Reduction with Zirconium Hydrides," Acc. Chem. Res., 13, $121(1980)$.

Wong, W.K., W. Tam, and J. A. Gladysz, "Electrophile-Induced Disproportionation of the Neutral Formyl $\left(\eta \cdot \mathrm{C}_{2} \mathrm{H}_{5}\right) \mathrm{Re}\left(\mathrm{PPh}_{3}\right)(\mathrm{NO})$ (CHO). Generation of Cationic Rhenium Carbenes of the Formula $\left[\left(\eta-\mathrm{C}_{2} \mathrm{H}_{5}\right) \operatorname{Re}\left(\mathrm{PPh}_{3}\right)(\mathrm{NO})(\mathrm{CHX})\right]^{+}\left(\mathrm{X}=\mathrm{H}, \mathrm{OCH}_{3}, \mathrm{OH}\right), " J . \mathrm{Am}$. Chem. Soc., 101, 5440 (1979).

Yermakov, Y. I., "Organometallic Compounds in the Preparation of Supported Catalysts," J. Mol. Catal., 21, 35 (1983).

Zwart, J., and R. Snel, "Metal Carbonyl Clusters in the Catalytic Hydrogenation of Carbon Monoxide," J. Mol. Catal., 30, 305 (1985).

Manuscript received Sept. 4, 1987, and revision received July 19, 1988. 